\title{
Antenatal Detection of Trisomy 21 from Mosaic Translocation in Uncultured Amniocytes by Interphasic FISH Henriette Poaty ${ }^{1,2,3 *}$, Dominique Carles $^{3}$ and Laurence Taine ${ }^{4}$
}

${ }^{1}$ Histology-Embryology and Genetic Laboratory, Faculty of Health Sciences, BP 2672, Marien Ngouabi University, Brazzaville, Congo ${ }^{2}$ National Research Institute on Health Sciences, Brazzaville, Congo

${ }^{3}$ Department of Fetopathology, CHU Pellegrin, Bordeaux, France

${ }^{4}$ Medical Genetics, Maternity, CHU Pellegrin, Bordeaux, France

\begin{abstract}
Introduction: We report a rare case of fetus having trisomy 21 from mosaic translocation. The purpose of this study was to present the interest of interphasic fluorescence in situ hybridization (FISH) performed on uncultured amniocytic cells in prenatal diagnosis of trisomy 21.

Patient and methods: From a pregnancy of 22 weeks old in 40 years old woman with a history of spontaneous miscarriage, chromosomal analysis (karyotype) has been done on trophoblast cells, in amniotic fluid cells, and combined with interphasic FISH performed on none cultured amniocytic cells associated to metaphasic FISH.

Results: Karyotype analysis revealed 46, XX, der (21; 21) (q10; q10), + 21 [17]/46, XX [3]. The trisomy 21 from mosaïc translocation was confirmed within 24 hours by interphasic nuclei from none cultured amniotic cells, then by metaphasic FISH.

Conclusion: The interphasic FISH analysis (in uncultured amniocytes) allows a quick and efficient prenatal diagnosis of aneuploidy, but it is a complementary analysis to other cytogenetic methods.
\end{abstract}

Keywords: Fluorescence in situ hybridization; Uncultured amniocytes; Trisomy 21; Robertsonian translocation; Mosaicism

\section{Introduction}

The trisomy 21 or Down syndrome is the most common chromosomal disorder with the incidence estimated between 1/700 to $1 / 1000$ live births, with a high risk in strong correlation with advanced maternal age $[1,2]$. The frequency is constant, regardless of the ethnic groups and the socio-economic conditions.

In most cases (86.6\% to 95\%), trisomy 21 is often free and homogeneous (present in all cells of the body and absence of translocation). It is a novo accident due to the meiotic chromosomal mal-segregation of the extra chromosome 21 , occurring much more in the first meiosis than in the second meiosis [3]. In those cases, outside maternal or paternal advanced age, other risk factors (such as alcohol, tobacco, environmental toxins, and unbalanced diet) are indexed especially among young mothers [3]. Recurrence risk is very low.

In $1 \%$ to $7.1 \%$ of cases, Down syndrome is secondary to a translocation $[3,4]$. In approximately $1 \%$ to $6.3 \%$ cases, it can be mosaicism (a part of the cells carries the anomaly) [3,5]. In the latter, it may also be a novo accident due to the mitotic chromosomal nondisjunction during the postzygotic period or inherited from one of the parents (non-disjunction in parental germs cells) with a recurrence risk.

The positive diagnosis is based on the ultrasound, the maternal serum markers and the cytogenetic examination. The ultrasound monitoring of the pregnancy allows detecting early abnormal ultrasound signs (AUS) such as: nuchal translucency superior to 3.5 $\mathrm{mm}$ in the first trimester of pregnancy. The routine first trimester combined test performed at 9-14 weeks gestational (WG) (maternal age, nuchal translucency at 11-12 WG, maternal serum markers at 13$14 \mathrm{WG}$ ) allows to calculate the percentage risk of trisomy 21 . It has a good predictive value. The second trimester combined test performed at 15-20 WG with less predictive value is recommended. In the event of anomaly, the antenatal diagnosis by amniocentesis (reference method) or by choriocentesis (good procedure in first trimester) is required.

The screening by maternal serum markers is based on the analysis of the combination of 3 to 4 markers. The markers most used are: alpha fetoprotein, beta human chorionic gonadotrophin ( $\beta-\mathrm{HCG})$, pregnancy-associated plasma protein A (PAPP-A), unconjugated estriol (uE3), S100 protein and inhibin-A (INH-A) [6]. The actual approach of research on cell-free fetal DNA (short fraction of $5 \%$ to $15 \%$, less than $200 \mathrm{bp}$ ) in maternal plasma (after ten WG), allows noninvasive prenatal diagnosis [7-9]. The diagnosis of certitude (in current practice) is done by the conventional cytogenetic (karyotype) and/or by the molecular cytogenetics: in situ hybridization fluorescent (FISH) or by array compared genomic hybridization (aCGH).

The aim of the present work is to show the interest of interphasic FISH technique from uncultured amniocytes. This study is based on a clinical observation of Down syndrome resulting from a mosaï translocation.

\section{Materials and Methods}

\section{Patients}

A retrospective observation of one trisomy 21 case was referred to the Medical Genetics Laboratory and the Fetoplacental Pathology unit of $\mathrm{CHU}$ of Pellegrin (Bordeaux). It was from Mrs. M, 40-year-old, married, nulliparous, with a history of five attempts to in vitro fertilization (IVF) and three gestations with two spontaneous miscarriages after IVF. Pregnancy studied (conceived by IVF) was 22 WG. The ultrasound of 12 WG seemed normal with a nuchal translucency of $1.4 \mathrm{~mm}$ and a length cranial-caudal (LCC) of $73 \mathrm{~mm}$. The reason for the consultation was advanced maternal age.

*Corresponding author: Henriette Poaty, Histology-Embryology and Genetic Laboratory, Faculty of Health Sciences, BP 2672, Marien Ngouabi University, Brazzaville, Congo, Tel: (00242) 0668657 61; E-mail: henriettepoaty@gmail.com

Received April 04 2017; Accepted May 12, 2017; Published May 15, 2017

Citation: Poaty H, Carles D, Taine L (2017) Antenatal Detection of Trisomy 21 from Mosaic Translocation in Uncultured Amniocytes by Interphasic FISH. Hereditary Genet 6: 180. doi:10.4172/2161-1041.1000180

Copyright: ( $\odot 2017$ Poaty H, et al. This is an open-access article distributed under the terms of the Creative Commons Attribution License, which permits unrestricted use, distribution, and reproduction in any medium, provided the original author and source are credited. 
Citation: Poaty H, Carles D, Taine L (2017) Antenatal Detection of Trisomy 21 from Mosaic Translocation in Uncultured Amniocytes by Interphasic FISH. Hereditary Genet 6: 180. doi:10.4172/2161-1041.1000180

\section{Methods}

\section{Cytogenetic analyses}

The diagnosis of certitude was based on the karyotype and the FISH (about fetus) performed on chorionic villus sampling (CVS) at 22 WG $(20 \mathrm{mg})$ and on the fetal amniotic fluid $(15 \mathrm{ml})$. The karyotype of parents proposed, was not made by refusal of the latter.

The karyotype on trophoblast after enzymatic dissociation (trypsin/ EDTA and collagenase) have benefited from a double technical: direct examination (without culture) of the trophoblast and cell culture extraembryonic mesenchymal tissue ( $\left.\mathrm{N}^{\circ} 12959-7\right)$.

On amniotic fluid ( $\left.{ }^{\circ} 5656\right)$ and trophoblast cultures, the karyotype have been done according to the standard procedures of blockage of cells multiplication in metaphase by the addition of colchicine, hypotonic shock, cells fixation by methanol/acetic acid. Karyotyping was performed by $\mathrm{R}$ banding using the thermic-Giemsa staining technique.

The FISH was performed using interphasic preparations of uncultured amniocytes and cytogenetic metaphasic preparations of CVS culture. The uncultured amniocytes were obtained according to usual procedures: centrifugation of amniotic fluid $(5 \mathrm{ml})$; addition of 5 $\mathrm{ml}$ trypsin/EDTA; hypotonic shock (with $5 \mathrm{ml}$ of KCL $0.56 \%$ ) in bath water for 20 minutes at $37^{\circ} \mathrm{C}$; cells fixation with methanol/acetic acid. The molecular probe pre-denatured used (marked in red and green), unique sequence of the 21q22.1-q22.2 region (D21S259, D21S341, D21S342 loci) has been obtained in commerce (Al. Technology). The FISH technique was done according to the standard procedures.

In brief:

i) Aged slides preparation (target) at $37^{\circ} \mathrm{C}$ and dehydratation in ethanol series $(70 \%, 80 \%, 90 \%$ and $100 \%)$.

ii) Target was denatured in denaturing solution (formamide $70 \%+$ $2 \mathrm{xSSC}+$ purified water) $\mathrm{pH} 7-8$ at $37^{\circ} \mathrm{C}$ and wash in ethanol series. The denatuturing probe mixture $(10 \mu \mathrm{l})$ was applied on the target.

iii) In situ hybridization of the probe and target was followed by incubation at $37^{\circ} \mathrm{C}$ overnight in humid chamber and post hybridization wash series (formamide $+\mathrm{SSC}$ ) at $45^{\circ} \mathrm{C}$.

iv) Signal was revealed by using the anti-digoxigenin antibody coupled to the FITC (Sigma), and the counterstain by the DAPI (two drops). v) Slide was observed on fluorescence microscope equipped with filters to visualize the fluorescence of cyanine (in red), the FITC (green) and DAPI (blue)

\section{Fetopathologic examination}

At the conclusion of cytogenetic results, and in order to research macroscopic and microscopic anomalies a fetopathologic examination has been requested by the parents.

\section{Results}

\section{Karyotype analysis}

On the trophoblast, examination after culture of CVS has highlighted a trisomy 21 from Robertsonian translocation 21; 21 from mosaic on 17 of 20 metaphases examined with a formula: $46, \mathrm{XX}$, der $(21 ; 21)$ (q10; q10), + 21 [17]/46, XX [3] (Figure 1A). Direct examination of CVS has confirmed the formula with the presence of trisomy 21 on 3 of 5 metaphases analyzed. The amniotic fluid has allowed the control of another origin, and the examination of 40 clones have highlighted on 2 different clones, the same anomaly with a low rate of mosaicism.

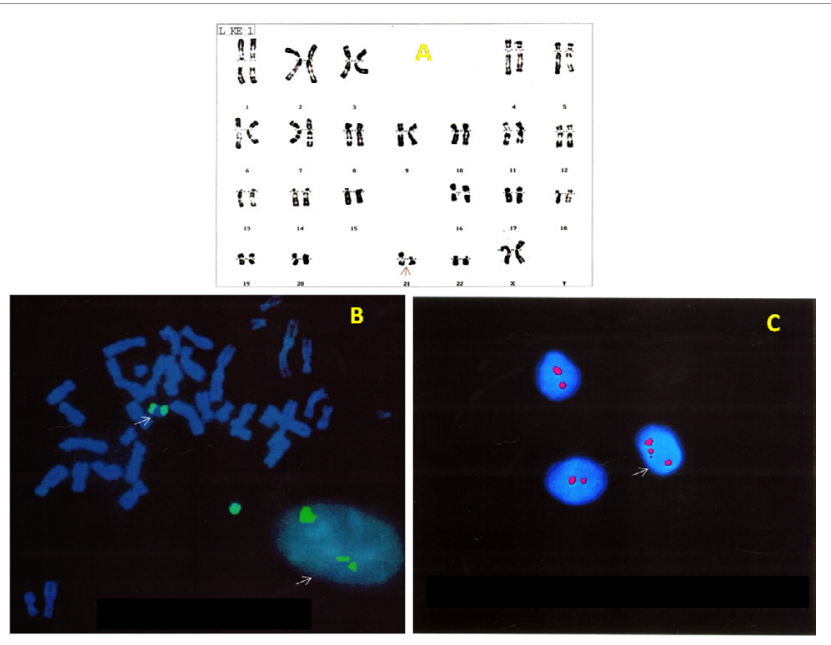

Figure 1: Cytogenetic results. A) Karyotype. Fusion of two homologous acrocentric chromosomes 21 (Robertsonian D/D translocation) and one associated chromosome 21 showing trisomy 21 from translocation. B) Chorionic villus sampling metaphase: presence of 3 signals of chromosome 21 (two in a doublet and one associated) in favour of a translocation. C) Uncultured amniocytes: presence of a triple signal in one interphasic cell nucleus, confirm the mosaic trisomy 21 .
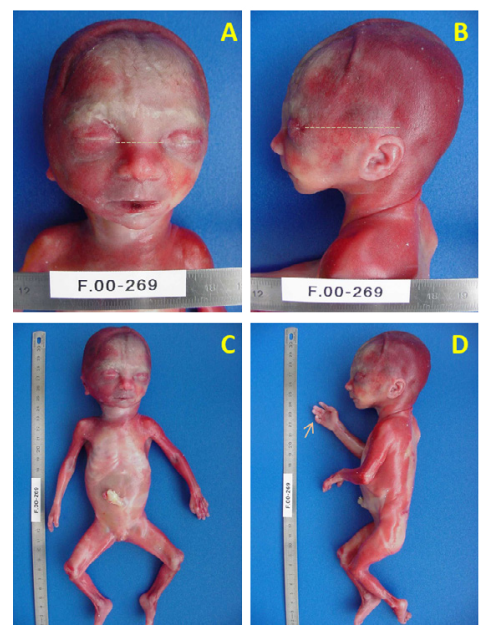

Figure 2: Morphological abnormalities. A), B) and C) Fetus of 22 weeks old carrier of a discrete facial dysmorphism: hypertelorism with a wide, flat nasal bridge, down and flat ears. D) Presence of bilateral clinodactyly of hand fifth finger: curvature of fifth finger toward fourth finger.

\section{FISH-analysis}

The cells culture of the CVS have permitted in 16 out of 18 mitosis to confirm the presence of a derivative $21: \operatorname{der}(21 ; 21)(\mathrm{q} 10 ; \mathrm{q} 10)$ (Figure 1B). On the uncultured amniocytes, in 24 hours, 100 nuclei per chromosome probe were examined and allowed the identification of 15 nuclei having a triple signal breaking down into doublet and one associated signal (Figure 1C). On an amniotic fluid witness, a triple signal was observed in $5 \%$ of the nuclei. The results of the karyotype and FISH showing trisomy 21 from mosaic translocation have motivated the medical interruption of pregnancy.

\section{Fetopathologic examination}

It has shown a female fetus (F.00-269) with discrete facial dysmorphism (hypertelorism, oblique palpebral fissures) (Figures 2A, 2B and $2 \mathrm{C}$ ) associated to extremities malformations: brachymesophalangy 
Citation: Poaty H, Carles D, Taine L (2017) Antenatal Detection of Trisomy 21 from Mosaic Translocation in Uncultured Amniocytes by Interphasic FISH. Hereditary Genet 6: 180. doi:10.4172/2161-1041.1000180

Page 3 of 4

and a bilateral clinodactyly of the hand fifth finger (Figure 2D) with transverse palmar crease. Autopsy was normal and the histological study showed only small signs of anoxia.

\section{Discussion}

The FISH is a molecular cytogenetic technique which allows visualizing specific sequences of nucleic acids on the chromosomes of metaphase or directly in the interphasic cell nuclei $[10,11]$. The results obtained about our patient demonstrate the reliability of prenatal diagnosis of trisomy 21 by the interphasic FISH on none cultured amniocytes.

In our observation, the number of cell nuclei to 3 signals being 15\%, the presence of trisomy 21 was strongly suspected, which had motivated to push the karyotype up to observation of 40 different clones, in order to highlight the anomaly. The karyotype alone on amniotic fluid cells and the absence of interphasic FISH, with a high probability, could lead to false negatives. The interphasic FISH, on none cultured amniocytes has enabled to confirm quickly the mosaicism and also the translocation (doublet) revealed by the karyotype.

Concerning translocation $21 \mathrm{q}$, in most cases, children do not exhibit any morphological anomalies [1]. However, there is a risk of $5 \%$ to $10 \%$ of having an abnormal phenotype as it is the case in the present observation. Translocation may be de novo with a recurrence of $1 \%$, or inherited from one of the parents and therefore not in relation with advanced maternal age (both parents are often the youngest) [3]. In an inherited form, recurrence (relatively high) is $20 \%$ if it is the mother who is involved and $10 \%$ if it is the father who is carrier of the anomaly [1]. In addition, chromosomal rearrangement especially balanced and Robertsonian translocations whose give higher risk of aneuploidy, are the most common anomalies found in couple having repetitive spontaneous abortions $[1,12]$.

Robertsonian translocation is the most frequent structural chromosomal rearrangement. It affects $1 \%$ of live births and concern acrocentric chromosomes 13, 14, 15, 21, 22 and Y [5,6]. It may be homologous: fusion of two identical acrocentric chromosomes (like in our fetus in which, both chromosomes 21 are fused); or not homologous: it concern two different acrocentric chromosomes, the most current are $\mathrm{t}(13 ; 14), \mathrm{t}(13 ; 21), \mathrm{t}(14 ; 21), \mathrm{t}(15 ; 21)[5,13,14]$. Result is a monocentric or dicentric chromosome [14]. In case of homologous Robertsonian translocation $21 \mathrm{q} ; 21 \mathrm{q}$, one parent is carrier of a translocation with a higher frequency from the mother [12]. In this case, the risk of having repetitive spontaneous miscarriages or children with Down syndrome is $100 \%[15,16]$. In the event of parental mosaicism, the risk of recidivism is greater than in a normal population [1]. This explains why a karyotype of parents, followed by a genetic counselling had been proposed.

The interphasic FISH on amniocytes none cultured as a method for antenatal diagnosis is used in current practice [17]. Thein et al. [18], in a series of 111 abnormal karyotypes, diagnosed easily in 48 to 72 hours, 97 aneuploidies (trisomy 21, 13, 18, triploidy and Turner). Most were associated with maternal advanced age, the AUS and the abnormal maternal serum markers. Spathas et al. [19] indicated that it is an informative method with many advantages. Indeed, it requires a small sample, allows the confirmation of the karyotype (longest technique, practicable only on metaphase cells) and implements a simplified method, quick with a very low rate of false positives. Indeed, in their series of six trisomies 21 examined, on 345 cell nuclei analyzed, there were $282(87.7 \%)$ of nuclei with 3 signals with a percentage of false positive zero and 3 (5\% and 5\%) false negative. Evans et al. [20] found that the interphasic FISH detects only $70 \%$ of cytogenetic

\begin{tabular}{|c|l|}
\hline Groups & Indications \\
\hline 1 & Maternal advanced age $\geq 35$ years old \\
\hline 2 & Rapid confirmation of an aneuploidy \\
\hline 3 & $\begin{array}{l}\text { Prenatal diagnosis of advanced pregnancies requiring a quick decision } \\
\text { with age < 35 years }\end{array}$ \\
\hline 4 & Translocation with difficult diagnosis \\
\hline 5 & $\begin{array}{l}\text { Group of high risk pregnancies with: AUS, abnormal MSM, parents with } \\
\text { chromosomal rearrangement or inherited genetic disease, couples with } \\
\text { children carrier of chromosomal abnormalities or recurrent miscarriages, } \\
\text { sex diagnosis for disease related to the X chromosome. }\end{array}$ \\
\hline AUS: Abnormal Ultrasound Signs; MSM: Maternal Serum Markers. \\
\hline
\end{tabular}

Table 1: Indications of interphasic FISH on uncultured amniocytes.

abnormalities. Indeed, Thein et al. [18], in their study, reported 14 cases not detected by interphasic FISH: which were deletion, translocation, insertion, mosaicism, and duplication.

For most authors [18-20], the interphasic FISH on uncultured amniocytes is a quick method for the detection of the most frequent aneuploidies (on chromosomes $21,13,18, \mathrm{X}, 8$ ). In addition, the quick confirmation of the results would reduce the mother anxiety. However, the method is not a first choice, but a complement to the karyotype, which identifies the abnormalities in number of chromosomes and structural abnormalities. With the help of our bibliographic references, we have summarized in Table 1, the main indications of interphasic FISH on uncultured amniocytes combined to the karyotype.

\section{Conclusion}

Interphasic FISH is an efficient and quick molecular cytogenetic method for diagnosis of certain trisomy 21 , and also of others common fetal aneuploidies. In addition it allows in case of amniocentesis to achieve directly a diagnosis on the uncultured amniocytes, method which finds a large indication in high risk pregnancies. However, the latter is not a substitutive technique to other methods but a complement of positive diagnosis. The method is easily applicable in African countries.

\section{Declarations}

a. Competing interests: The authors have no conflict interest to declare.

\section{b. Funding: This work was not funded by any organization.}

c. Author's contributions: Laurence Taine and Henriette Poaty conceived and designed the study. Laurence Taine, Dominique Carles and Henriette Poaty performed the study and analyzed the data. Henriette Poaty wrote the paper.

\section{Acknowledgements}

We are grateful to Dr. Denis Bedat for his English translation and all contributors that have read and approved the manuscript.

\section{References}

1. Pazarbasi A, Demirhan O, Alptekin D, Ozgunen F, Ozpak L, et al. (2013) Inheritance of chromosome 3 and 21 Translocation in the fetuses, with one also having trisomy, in three pregnancies in one family. Balkan J Med Genet 16: 91-96.

2. Dechamps F, Faure M (1998) Trisomie 21. Atlas échographique. Des malformations congénitales du Fœtus, Sauramps Medical 2: 373-378.

3. Sotonica M, Mackic-Djurovic M, Hasic S, Kiseljakovic E, Jadric R, et al. (2016) Association of parental age and the type of Down syndrome on the territory of Bosnia and Herzegovina. Med Arch 70: 88-91.

4. Baruffi MR, Souza DH, Silva RA, Ramos ES, Moretti-Ferreira D (2013) A rare non Robertsonian translocation involving chromosomes 15 and 21. Sao Paulo Med J 131: 427-431. 
Citation: Poaty H, Carles D, Taine L (2017) Antenatal Detection of Trisomy 21 from Mosaic Translocation in Uncultured Amniocytes by Interphasic FISH. Hereditary Genet 6: 180. doi:10.4172/2161-1041.1000180

5. Mutton D, ALberman E, Hook EB (1996) Cytogenetic and epidemiological findings in Down syndrome, England and Wales 1989 to 1993. National Down syndrome cytogenetic register and the association of clinical cytogeneticists. J Med Genet 33: 387-394.

6. Huang S, Chang C, Cheng P, Hsiao C, Soong Y, et al. (2014) First-trimester combined screening is effective for the detection of unbalanced chromosomal translocations at 11 to 12 weeks of gestation. Reprod Sci; 21: 594-600.

7. Lo JO, Cori DF, Norton ME, Caughey AB (2014) Non-invasive prenatal testing. Obstet Gynecol Surv 69: 89-99.

8. Gekas J, Langlois S, Ravitsky V, Audibert F, Van den Berg DG, et al. (2014) Identification of trisomy 18 , trisomy 13 , and Down syndrome from maternal plasma. Appl Clin Genet 7: 127-131.

9. Yu SC, Chan KC, Zheng YW, Jiang P, Liao GJ, et al. (2014) Size-based molecular diagnostics using plasma DNA for noninvasive prenatal testing. PNAS 111: 8583-8588.

10. Belaud-Rotureau MA, Parrens M, Dubus P, Turmo M, Lacroute G, et al. (2002) Interphase FISH analysis on histologic sections of fixed tissues for $\mathrm{t}(11 ; 14)$ (q13; q32) detection in mantle cell lymphoma and $\mathrm{t}(8 ; 14)$ (q14; q32) in Burkitt's lymphoma. Ann Pathol 22: 145-149.

11. Vignaud JM, Plenat F, Duprez A (1990) In situ hybridization: Principles, methods and applications. Arch Anat Cytol Path 38: 125-134.

12. Pal S, Ma SO, Norhasimah M, Suhaida MA, Siti Mariam I, et al. (2009) Chromosomal abnormalities and reproductive outcome in Malaysian couples with miscarriages. Singapoure Med J 50: 1008-1012.
13. Bint SM, Ogilvie CM, Flinter FA, Khalaf Y, Scriven PN (2011) Meiotic segregation of Robertsonian translocations ascertained in cleavage-stage embryoimplication for preimplantation genetic diagnosis. Hum Reprod 26: 1575-1584.

14. Wolff D J, Schwartz S (1992) Characterization of Robertsonian translocations by using fluorescence in situ hybridization. Am J Hum Genet 50: 174-181.

15. kolgeci S, Azemi M, Ahmeti H, Dervishi Z, Sopjani M (2012) Recurrent abortions and down syndrome resulting from Robertsonian translocation 21q; 21q. Med Arch 66: 350-352.

16. Sudha T, Gopinath PM (1994) Homologous Robertsonian translocation (21q21q) and abortions. Hum Genet 85: 253-255.

17. Zhang WG, Zhang WQ, Dai MZ, Chen XJ, Zhang Y, et al. (2013) Application of combined fluorescence in situ hybridization and karyotype analysis for the diagnosis of Roberstsonian translocation type 21. Zhonghua Yi Xue Yi Chuan Xue Za Zhi 30: 210-213.

18. Thein AT, Abdel-Fattah SA, Kyle PM, Soothill PM (2000) An assessment of the use of interphasic FISH with chromosome specific probe as an alternative to cytogenetics in prenatal diagnosis. Prenat Diagn 20: 275-280.

19. Spathas DH, Divane A, Maniatis GM, Ferguson-Smith ME, Ferguson-Smith MA (1999) Prenatal detection of trisomy 21 in uncultured amniocytes by fluorescence in situ hybridization: A prospective study. Prenatal Diagn 14: 1049-1054.

20. Evans MI, Henry GP, Miler WA, Bui TH, Snidjers RJ, et al. (1999) International collaborative assessment of 146,000 prenatal karyotypes: expected limitation if only chromosome-specific probes and fluorescent in-situ hybridization are used. Hum Reprod 14: 1213-1216. 